\title{
Appraisal of the research grant schemes of the World Health Organization Regional Office for the Eastern Mediterranean: the way forward
}

O. Shideed ${ }^{7}$ and N. Al-Gasseer ${ }^{2}$

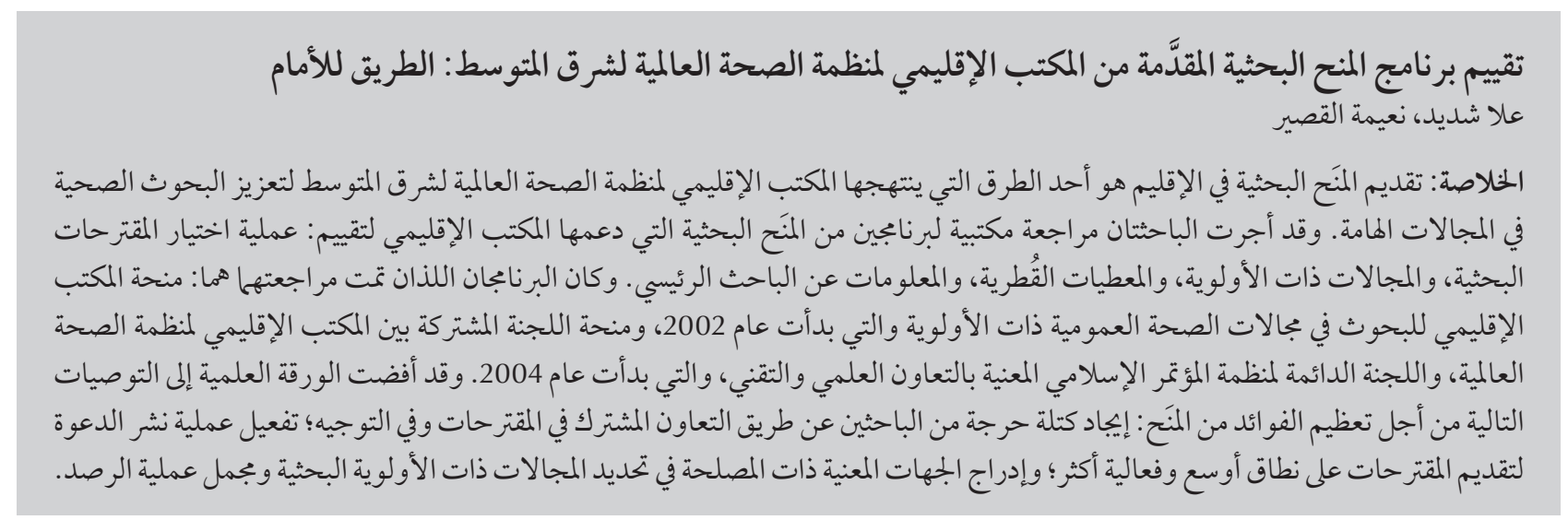

ABSTRACT One way that the World Health Organization Regional Office for the Eastern Mediterranean (EMRO) promotes the important area of health research is by providing research grants within the Region. A desk review of 2 of the EMRO-supported research grant schemes was done to assess: the selection process of the research proposals, the priority areas, country data and information on the principal investigator. The 2 schemes were: EMRO grant for Research in Priority Areas of Public Health, started in 2002, and the EMRO and Organization of Islamic Conference Standing Committee for Science and Technological Cooperation Grant for Research in Applied Biotechnology \& Genomics in Health, started in 2004. The paper proposes the following recommendations to enhance benefit from the grant process: create a critical mass of researchers through joint collaboration in proposals and mentoring; instigate a more rigorous process to disseminate the call for proposals more widely and effectively; and include relevant stakeholders in the identification of priority areas for research and overall monitoring of the process.

Évaluation et orientations futures des programmes de subventions à la recherche du Bureau régional de l'Organisation mondiale de la Santé pour la Méditerranée orientale

RÉSUMÉ Les subventions à la recherche dans la Région sont l'une des méthodes choisies par le Bureau régional de I'Organisation mondiale de la Santé (OMS) pour la Méditerranée orientale pour promouvoir le domaine essentiel de la recherche en santé. Une analyse documentaire des deux programmes de subventions à la recherche soutenus par le Bureau régional a été réalisée pour évaluer les points suivants : le processus de sélection des propositions de recherche, les domaines prioritaires, les données de pays et les informations concernant le chercheur principal. Les deux programmes étaient les suivants : subventions à la recherche dans les domaines prioritaires de la santé publique (lancé en 2002), et subventions conjointes destinées à soutenir la recherche en biotechnologie et génomique appliquées à la santé, accordées par le Bureau régional et le Comité permanent pour la coopération scientifique et technologique de l'Organisation de la Conférence islamique (qui existe depuis 2004). L'article énumère des recommandations susceptibles de renforcer les effets bénéfiques des programmes de subvention: former un nombre suffisant de chercheurs grâce à une collaboration sur les propositions et au tutorat ; instaurer un processus plus rigoureux pour diffuser les appels à propositions plus largement et plus efficacement; et impliquer les parties intéressées dans l'identification des domaines prioritaires pour la recherche et le suivi global du processus.

${ }^{7}$ Research Policy and Cooperation Unit, World Health Organization, Regional Office for the Eastern Mediterranean, Cairo, Egypt. ${ }^{2}$ World Health Organization, Regional Office for the Eastern Mediterranean, Cairo, Egypt.

Received: 05/01/12; accepted: 20/03/12 


\section{Introduction}

The research for health landscape has changed since the introduction of the term "10/90 gap" in 1990 [1]. Overall investments in research for health have increased. However, this is coupled with an epidemiological transition in many countries burdening them with increased chronic diseases while still struggling with infectious and communicable diseases. Nevertheless, the term "10/90 gap" is still valid referring to the mismatch between the investments in research for health and the emerging needs of the communities. This is further referred to in the WHO strategy on research for health, "Investments in health research are insufficient; further, they are not appropriately directed towards tackling priority health problems" [2].

The Eastern Mediterranean Region has witnessed an increase in investments in research in general; investment in the Islamic Republic of Iran rose from $0.59 \%$ of GDP in 2006 to $4 \%$ today and in Tunisia from $0.03 \%$ in 1996 to $1.25 \%$ in 2009, and Qatar aims to spend $2.8 \%$ of GDP on research by 2015 [3]. Nonetheless, the proportion of investment allocated to research for health is still less than desired.

As part of the World Health Organization's (WHO) mandate as a knowledge-based organization, and in accordance with its constitution, one of its important functions is, "to promote and conduct research in the field of health" [4]. Additionally, in the Eleventh General Programme of Work, one of WHO's 6 core functions is, "Shaping the research agenda and stimulating the generation, translation and dissemination of valuable knowledge" [5].

The WHO Regional Office for the Eastern Mediterranean (EMRO) has continuously promoted and highlighted the importance of research for health in providing the evidence necessary to inform health policy, planning and practice. It is within this context that since the establishment of the Advisory Committee on Health Research (ACHR) in EMRO in 1976 (known then as the Regional Advisory Committee on Biomedical Research), EMRO has supported a considerable number of research proposals received from researchers across the Region [6]. The priority areas for such research have focused on the emerging needs of the countries in the Region.

The purpose of this paper is to provide an overview of the EMROsupported research grants. The review was initiated as part of the process towards developing the strategic directions for scaling up research for health in the Eastern Mediterranean Region, which were endorsed by the ministers of health during the 58th Session of the Regional Committee in October 2011 [7]. The initial results of the review were presented during the 25th Session of the Advisory Committee on Health Research (ACHR) in October 2010, for its deliberations and recommendations [8].

Currently there are 3 research grant schemes through which EMRO awards funding to researchers from the Region: one is administered and managed by the Division of Communicable Diseases (DCD), and the other 2 are administered and managed by the Research Policy and Cooperation unit (RPC).

\section{EMRO grant for Tropical Disease Research, DCD, 1992- present}

The Tropical Disease Research (TDR) grants focus on tropical diseases relevant to the Region, namely malaria, schistosomiasis, tuberculosis, leishmaniasis and lymphatic filariasis. These areas were further expanded in 2002 to include other communicable diseases: HIV/AIDs and sexually-transmitted diseases, vaccine-preventable diseases, haemorrhagic fevers, brucellosis, meningitis and echinococcosis [9]. The objectives of the grant are to: strengthen operational research in tropical and other communicable diseases in the Region; support research that contributes to the prevention and control of tropical and other communicable diseases; and strengthen the research capacity of researchers in the Region.

In response to the previous 16 calls for applications for the EMRO TDR grants from 1992 to 2008, 346 proposals have been funded in the Region, out of a total of 2341 proposals submitted, a funding rate of $15 \%$ [9]. The researchers are granted 12 months to conduct their research projects or it may be considered the first phase (12 months) of a 24-month project, with funding of up to US\$20000.

\section{EMRO grant for Research in Priority Areas of Public Health, RPC, 2002-present}

The main objective of the grant for Research in Priority Areas of Public Health (EMRPPH) is to enhance and promote the sustainability and efficiency of health systems in the countries of the Region. The specific objectives are to: generate knowledge relevant to local priority problems and issues of public health importance with special emphasis on health systems research; help in capacity building for research through learning by doing and hands on training; strengthen the link between research and policy/decision making; and enhance the exchange of experiences between the countries in the region.

The EMRPPH grant is open to all researchers in health from the Region, through a competitive selection process. The researchers are granted approximately 9 months to conduct their research projects, with funding of up to US\$ 10000 . The announcement process for the calls has been done by: email to all technical units in EMRO requesting them to share the call with interested researchers and scientists; email to WHO Representative Offices (WRO) in Member States requesting them to inform the Ministry of Health, 
WHO Collaborating Centres, academia, medical and public health research institutes, and other interested partners; email to all researchers who have submitted proposals to the previous calls; and announcement on the EMRO website.

\section{EMRO and COMSTECH Grant for Research in Applied Biotechnology \& Genomics in Health, RPC, 2004-present}

The EMRO and Organization of Islamic Conference Standing Committee for Science and TechnologicalCooperation (COMSTECH) Grant for Research in Applied Biotechnology \& Genomics in Health (RAB\&GH) was initiated in response to Regional Committee resolution EM/RC51/R.11 which requested EMRO to, "facilitate and provide opportunities for exchange and sharing of knowledge and information on genomics technology" and, "foster partnerships among the main stakeholders and contribute to capacity-building and resource mobilization" [10].

The main objective of the grant is to focus on the application of biotechnological and genomic techniques to strengthen health systems and improve health care. Additionally, one of the main purposes is to support regional collaboration for the conduct of applied research. The collaboration among researchers from different organizations/ institutions in the countries is expected to: synergize the process to overcome obstacles and manage the necessary interdependencies involved in research in genomics and biotechnology; make services more accessible and effective; increase the integration of research results into other sectors (e.g. industry, government agencies or departments, community groups, universities) and offer opportunities to aid the dissemination of results; diversify capability to accomplish tasks (e.g. provide opportunities for trainees to spend time in different laboratories, exchange of data and experience between institutions and sectors); and foster ties between researchers in the academic, community, private and public sectors. The researchers are granted approximately 18 months to conduct their research projects, with funding up to US\$ 15000 .

The main focus of this paper is a review of the latter 2 grant schemes, administered by the RPC unit in EMRO.

\section{Methods}

A desk review was conducted of the RPC unit's grant database. Information for both schemes, EMRPPH and RAB\&GH, was retrieved. The data collected included: title of the submitted proposal, country of submission, name of the principal investigator (PI), and the funds granted for the selected proposals. The priority area which the proposal addressed for the EMRPPH grant was not mentioned in the database, therefore, as an alternative, 3 categories (health systems and services, health promotion and protection, and communicable diseases) were identified and the proposals were classified based on the title provided. For some cases, the title alone was not indicative of the priority area that the proposal addressed and was thus marked as "not specified".

With regard to the 2010-2011 rounds for both schemes, more information was retrieved from the application forms of the submitted proposals. In addition to the information mentioned above, gender and discipline of the PI were obtained. Additionally, for the EMRPPH grant, the specific priority areas as stated by the PI were considered and for the RAB\&GH grant, the age of the PI was noted.

\section{Results}

\section{EMRPPH 2002-2008}

In response to the previous 6 calls for applications for the EMRPPH grant 2002-2008, 143 proposals were funded in the Region (Figure 1), out of 935 submitted proposals (a funding rate of 15.3\%). It is also evident from Figure 1 that in some cases the same researchers were funded in different years. As mentioned in the methods section, the priority area was not stated in the data available for 2002-2008, so the title of the proposal was used as a proxy for this. Throughout the years, the majority of the proposals addressed health protection and promotion areas (noncommunicable diseases, mental health and substance abuse, nutrition, maternal and child health, environmental determinants of health, etc.) followed by health systems and services (Figure 2).

\section{Review process of EMRPPH 2002 2008 submissions}

Internal review: All the proposals received are screened by the RPC unit and those qualifying for the grant (meeting the eligibility criteria set out in the guidelines and application form) are reviewed to assess relevance to the specified priority areas and are scored on an evaluation form.

Final selection committee: The qualifying proposals are sent to the final selection committee, an independent committee formed of experts from the Region. The proposals are reviewed to assess the overall merit of the proposed research, and the committee members provide their feedback regarding the proposals assigned to them. The final recommendations are set and accordingly the proposals to be funded are identified. The selected proposals are then reviewed to ensure ethical considerations have been taken into account in research involving human participants. The ethical review is carried out by a separate committee, the EMRO Ethics Review Committee.

\section{EMRPPH 2010-2011}

In response to the seventh call for research protocols for the EMRPPH grant for 2010-2011,84 proposals were received from researchers in the Region (Figure 3). 

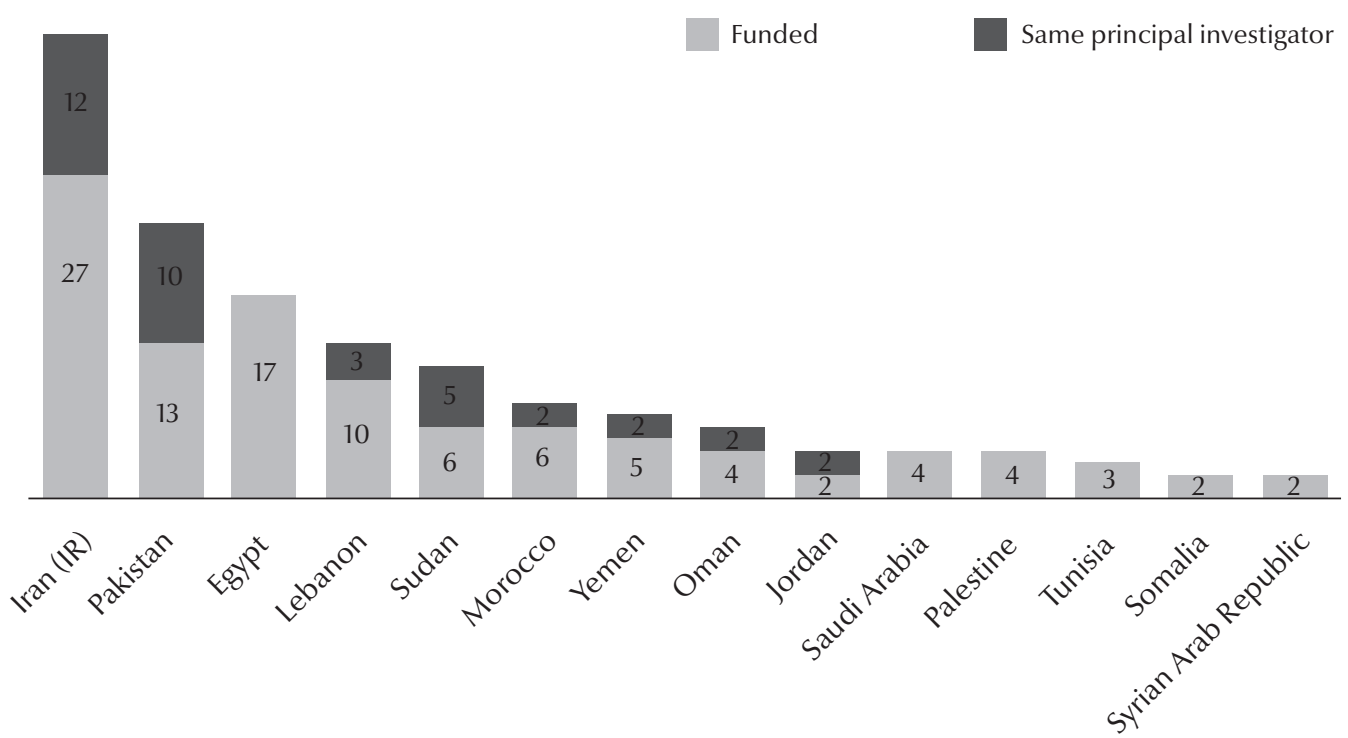

Figure 1 Distribution of funded proposals $(n=143)$ by member country: EMRO grant for Research in Priority Areas of Public Health 2002-2008

Review process of EMRPPH 2010 2011 submissions

A different approach was followed in the review process of the applications submitted for the 2010-2011 EMRPPH grant.

Internal review: all the proposals received were screened and those qualifying for the grant were categorized and sent to the relevant technical unit within the various divisions of the Regional Office. Proposals were reviewed by the technical unit to assess relevance to the specified priority areas and overall merit of the study, scored on an evaluation form. Responses were received from the technical units and summarized and proposals which were recommended by the technical units were sent for external review.

External review: a number of prominent researchers and academicians from the Region were identified and an independent committee formed, with multidisciplinary membership and gender balance. The review was done virtually (through

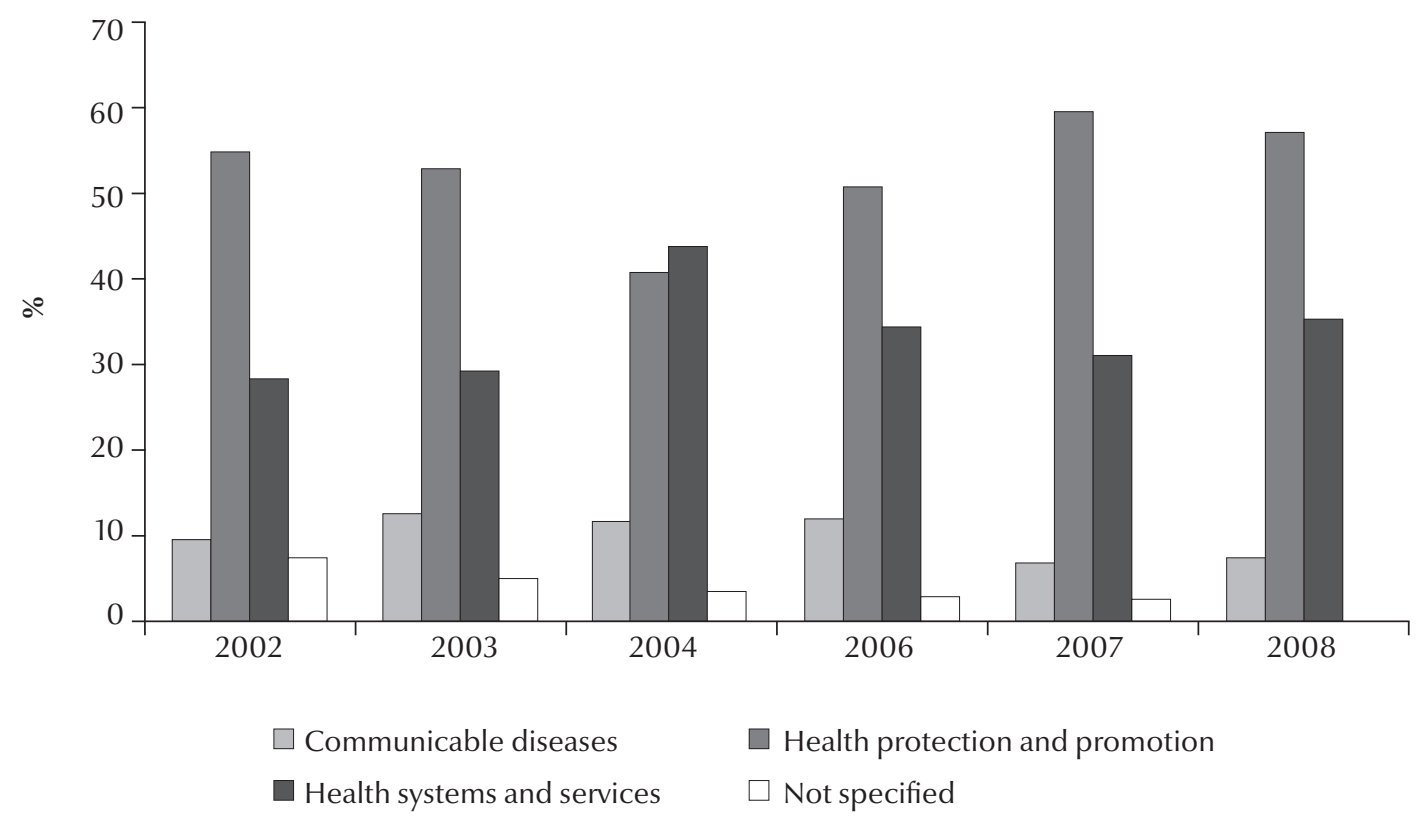

Figure 2 Distribution of priority areas of proposals submitted $(n=935)$ by year: EMRO grant for Research in Priority Areas of Public Health 2002-2008 


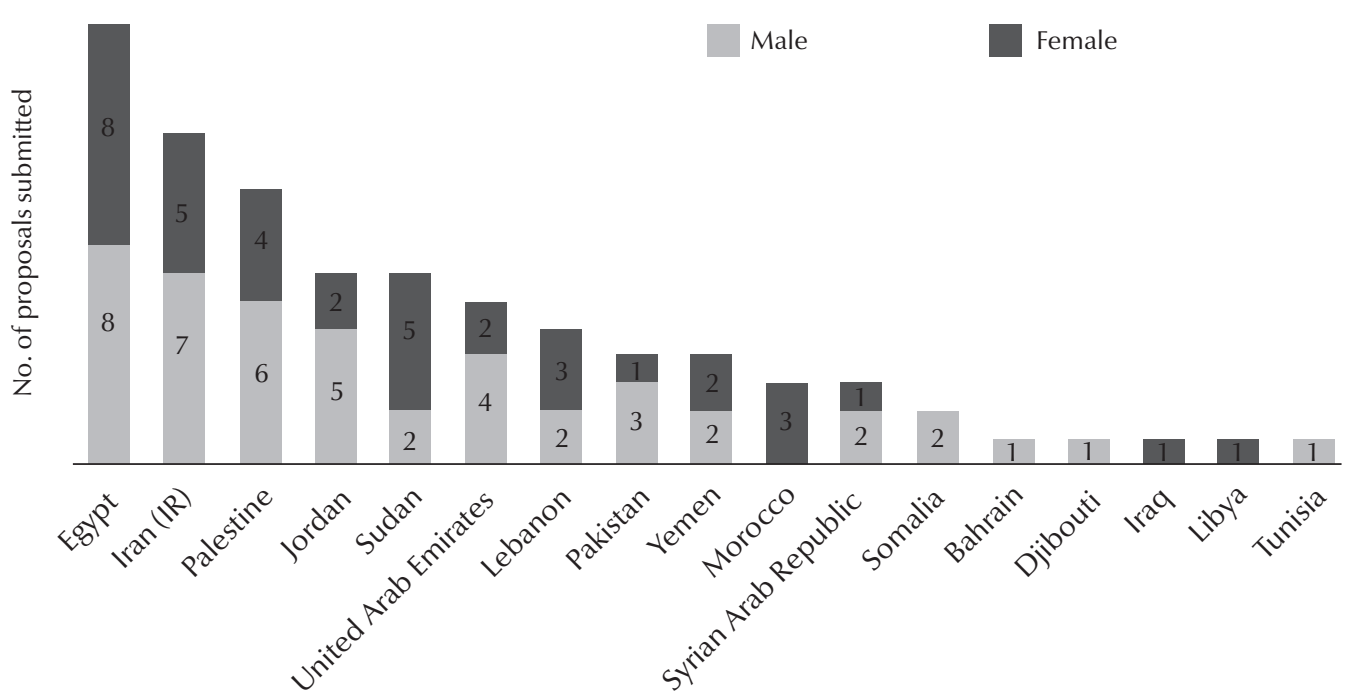

Figure 3 Distribution of submitted proposals $(n=84)$ by member country and sex of the principal investigator: EMRO grant for Research in Priority Areas of Public Health 2010-2011

emails and teleconference) in this round. The short-listed proposals were sent to the committee members for review; each proposal was sent to 2 reviewers. The proposals were reviewed to assess the overall merit of the proposed research and the scientific soundness of the proposal. Once the final recommendations of the external reviewers were received, the proposals selected for funding were compiled. The ethical review process is similar to that mentioned earlier.

\section{Descriptivecharacteristics of EMRPPH 2010-2011 submissions}

A total of 84 proposals were received from researchers from 17 Member States of the Region (Figure 3). There was a gender balance with regard to the PI: in $55 \%$ of the submissions the PI was male. Age data were available for $60 \%$ of the PIs; in some cases the date of birth was not stated so an approximate calculation was made based on the years of education stated. The average age of PIs was 45.5 years (range 29-60 years). The PIs came from a broad range of disciplines (data were available for $66 \%$ of the submitted proposals): $35 \%$ had a background in public health, $31 \%$ in medicine, $13 \%$ in nursing, $7 \%$ in biomedical sciences, 5\% each in pharmacology and nutrition and $4 \%$ in dentistry.

The distribution of the submitted proposals among the priority areas assigned for the EMRPPH 2010-2011 grants, as mentioned by the PIs in the application were:

- Climate change and environmental health (5 proposals)

- Preparedness, risk reduction and response to emergencies and disasters: man-made and natural (1 proposal)

- Knowledge generation leading to evidence-informed health policy (36 proposals)

- Assessment of the burden of noncommunicable diseases: cancer, diabetes, cardiovascular and renal diseases ( 23 proposals)

- Development and sustainability of community ownership in socioeconomic and health-related interventions ( 1 proposal)

The remaining 18 proposals submitted were categorized as "unspecified by PI", i.e. those that did not have a specified priority area indicated on the application form, yet after review were found to address at least one of the priority areas.
Priority area identification for the EMRPPH has used several methods over the years. In some instances priorities were set by: a task force assembled for this reason; contribution of technical units in EMRO which identified priority areas relevant to their work; discussions during ACHR meetings; emerging global and regional priorities.

\section{RAB \& GH 2004-2008}

In response to the previous 3 calls for applications for the EMROCOMSTECH Grant for RAB\&GH 2004-2008, 48 proposals were funded in the Region, out of 212 submitted proposals (a funding rate of $23 \%$ ).

\section{Review process of RAB\&GH submis- sions}

Initial review: all the proposals received are initially screened by the RPC unit, and those qualifying for the grant (meeting the eligibility criteria set out in the guidelines and application form) are short-listed.

External review: this is done by a selection committee identified jointly by WHO/EMRO and COSMTECH and comprising renowned health researchers from the Region who are specialists in the research areas specified in the RAB\&GH grant. Each member of 
the committee is requested to critically examine the proposals pertaining to his/her area of specialization either as primary or secondary reviewer. A meeting of the selection committee is then held and the proposals are presented by the reviewers and discussed by the committee members. Each proposal is scored and the decision for funding is finalized. The members of the selection committee usually consider the merit of the research protocol, degree of collaboration and expected impact of the proposed research on national and regional health issues. The ethical review process is similar to that mentioned earlier.

\section{RAB\&GH 2010-2011}

In response to the fourth call for applications for the EMRO-COMSTECH 2010-2011,30 proposals were received from researchers from the Region. All the submitted proposals were of a collaborative nature except for one, which was an individual submission.

\section{Descriptive characteristics of the $R A B$ \& GH 2010-2011 submissions}

The 30 proposals received were from researchers from 6 Member States (Figure 4). For $53 \%$ of the submissions the PI was a male. Age data were available for $60 \%$ of the PIs; in some cases the date of birth was not stated so an approximate calculation was made based on the years of education stated. The average age of the PIs was 51 years (range 31-73 years). The PIs of the submitted proposals came from a broad range of disciplines (the data were available for $90 \%$ of the PIs) with the majority from medical and clinical sciences backgrounds (78\%). Medical and clinical sciences here refer to; biotechnology $(n=2)$, molecular biology $(n=6)$, microbiology $(n=4)$, organic chemistry $(n=1)$, biochemistry $(n=$ $2)$, parasitology $(n=1)$ and genetics $(n=2)$. The other 2 disciplines were medicine and public health with $18.5 \%$ and $3.5 \%$ respectively.

\section{Discussion}

As part of its commitment to promoting research for health in the Region through providing both technical and financial support, EMRO has managed to reach a broad range of researchers in the Region. The research grants that EMRO provides to researchers have also contributed to capacity-strengthening in terms of developing researchers' ability to conduct research from the design to dissemination phase. The submitted proposals varied by country, and in some instances were from the same researchers. This may indicate a number of issues: the dissemination of the call for proposals is limited and therefore reaching the same audiences; the amount of the grant fund is not attractive for researchers; the priorities are of interest to a specific group; the language of the grant (English) may pose a barrier; or this may be a reflection of research for health capacity in the country. Increased attention needs to be given to countries with no or few submissions to assess the reasons for low submissions and address impediments, if any. From the desk review, there was neither documented nor accessible information on the ability or success of EMRO in reaching researchers in countries that have low or no submissions. Furthermore, the relationship between EMRO's active work in capacity-building in research methodology and the actual conducting of research is difficult to assess with the current degree (number and quality) of submissions.

Setting priorities for research for health is vital to ensure maximum benefit from funds allocated for research for health [11]. Priority setting is a complex process as there are many factors (e.g. availability of funds, feasibility, public health benefit, etc.) that contribute to it, and thus "one-size fits all" is not applicable in this case. There is a need to revisit the various processes EMRO has been following in setting research for health priorities and identify a more systematic

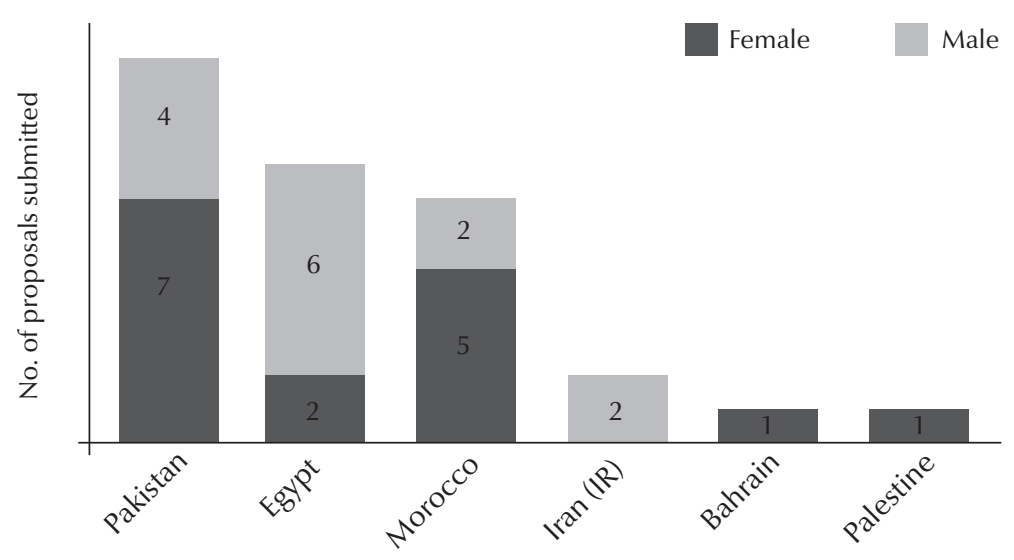

Figure 4 Distribution of submitted proposals $(n=30)$ by member country and sex of the principal investigator: grant for Research in Applied Biotechnology \& Genomics in Health 2010-2011 
approach taking into consideration the checklist proposed by Viergever et al. where they identify 9 common themes of good practice for identifying research for health priorities [12]. Moreover, in both the global and regional research for health strategies, the 2010 WHO Strategy on research for health [2] and the 2011 strategic directions for research for health in the Eastern Mediterranean Region [7] respectively, one of the goals is priorities. This goal refers to setting priorities for research for health that respond to national, regional and global needs.

The following recommendations for the development of the EMRPPH process are proposed based on this review and in line with the deliberations of the ACHR members during the Committee's 25 th session and research for health stakeholders during a consultative expert meeting in preparation of the strategic directions for scaling up research for health in the Eastern Mediterranean Region

- Involve stakeholders in the grant process from the beginning (i.e. in selection of priority areas, screening of the proposals, following the progress, etc.).

- Provide grants with the aim of creating a critical mass of researchers who can transfer the knowledge and skills of grant proposal writing for research for health, by strengthening research capacity through direct mentoring of researchers at the national level on writing research proposals.

- Provide technical support for researchers, as needed, with the grant application, completion of the grant, and dissemination and utilization of the results.
- Encourage experienced researchers to collaborate with newcomers in developing joint research proposals.

- Encourage and support researchers to disseminate their research results with concerned individuals and institutions at the national level, and regional/global level as appropriate.

The main focus of this paper has been on the process of identifying the priorities, announcing the call and selecting proposals for funding. It is strongly recommended that this work to be further strengthened by conducting a standardized assessment of the quality of the research implemented, whether it achieved the specified objectives of the proposal, and the impact that this research has had, whether at national or regional levels.

\section{References}

1. Health Research: essential link to equity in development. New York, The Commission on Health Research for Development, Oxford University Press, 1990.

2. World Health Organization's role and responsibilities in health research. Geneva, World Health Organization, 2010 (WHA 63/22) (http://apps.who.int/gb/ebwha/pdf_files/WHA63/ A63_22-en.pdf, accessed 28 March 2012).

3. Knowledge, networks and nations: Global scientific collaboration in the 21st century. London, The Royal Society, 2011.

4. Constitution of the World Health Organization. In: Basic documents, 45th ed. (Suppl.). Geneva, World Health Organization, 2006.

5. Engaging for health: Eleventh General Programme of Work 2006-2015: a global health agenda. Geneva, World Health Organization, 2006 (http://whqlibdoc.who.int/publications/2006/GPW_eng.pdf, accessed 28 March 2012).

6. World Health Organization, Regional Office for the Eastern Mediterranean. Research Policy and Cooperation. Renewed regional Strategy for Health Research for Development (http://www.emro.who.int/rpc/policy.htm, accessed 28 March 2012).

7. Fifty-eighth Session of the Regional Committee for the Eastern Mediterranean, September 2011. Technical paper. Strategic directions for scaling up research for health in the Eastern Mediterranean Region (EM/RC58/6), 2011 (http://www.emro.who. int/rc58/PDF/EMRC58_06en.pdf, accessed 28 March 2012).
8. Twenty-fifth session of the Eastern Mediterranean Advisory Committee on Health Research: report to the Regional Director. Cairo, World Health Organization, Regional Office for the Eastern Mediterranean, 2010. (http://www.emro.who.int/rpc/ACHR. htm, accessed 28 March 2012).

9. World Health Organization, Regional Office for the Eastern Mediterranean. Operational research in tropical and communicable diseases: History and progress. Cairo [webpage] (http://www.emro.who.int/tdr/history.htm, accessed 28 March 2012)

10. Fifty-first Session of the Regional Committee for the Eastern Mediterranean Cairo, Egypt, 3-6 October 2004. Resolutions. Development and use of genomics and biotechnology for public health (Resolution EM/RC51/R.11) (www.emro.who. int/governance/PDF/RC51_Resolutions.pdf, accessed 28 March 2012).

11. Bamako call to action on research for health: Strengthening research for health, development and equity. From the Global Ministerial Forum on Research for Health Bamako, Mali, November 17-19, 2008 (http://www.who.int/rpc/ news/BAMAKOCALLTOACTIONFinalNov24.pdf, accessed 28 March 2012).

12. Viergever $\mathrm{R}$ et al. A checklist for health research priority setting: nine common themes of good practice. Health Research Policy and Systems, 2010, 8:36. 